\title{
Development and characterization of BAC-end sequence derived SSRs, and their incorporation into a new higher density genetic map for cultivated peanut (Arachis hypogaea L.)
}

Hui Wang ${ }^{1,4}$, R Varma Penmetsa ${ }^{2}$, Mei Yuan ${ }^{1}$, Limin Gong ${ }^{3}$, Yongli Zhao ${ }^{4}$, Baozhu Guo ${ }^{5}$, Andrew D Farmer 6 , Benjamin D Rosen ${ }^{2}$, Jinliang Gao ${ }^{2}$, Sachiko Isobe, David J Bertioli ${ }^{8}$, Rajeev K Varshney ${ }^{9}$, Douglas R Cook $^{2}$ and Guohao $\mathrm{He}^{3^{*}}$

\begin{abstract}
Background: Cultivated peanut (Arachis hypogaea L.) is an important crop worldwide, valued for its edible oil and digestible protein. It has a very narrow genetic base that may well derive from a relatively recent single polyploidization event. Accordingly molecular markers have low levels of polymorphism and the number of polymorphic molecular markers available for cultivated peanut is still limiting.

Results: Here, we report a large set of BAC-end sequences (BES), use them for developing SSR (BES-SSR) markers, and apply them in genetic linkage mapping. The majority of BESs had no detectable homology to known genes (49.5\%) followed by sequences with similarity to known genes (44.3\%), and miscellaneous sequences (6.2\%) such as transposable element, retroelement, and organelle sequences. A total of 1,424 SSRs were identified from 36,435 BESs. Among these identified SSRs, dinucleotide (47.4\%) and trinucleotide (37.1\%) SSRs were predominant. The new set of 1,152 SSRs as well as about 4,000 published or unpublished SSRs were screened against two parents of a mapping population, generating 385 polymorphic loci. A genetic linkage map was constructed, consisting of 318 loci onto 21 linkage groups and covering a total of 1,674.4 cM, with an average distance of $5.3 \mathrm{cM}$ between adjacent loci. Two markers related to resistance gene homologs (RGH) were mapped to two different groups, thus anchoring 1 RGH-BAC contig and 1 singleton.

Conclusions: The SSRs mined from BESS will be of use in further molecular analysis of the peanut genome, providing a novel set of markers, genetically anchoring BAC clones, and incorporating gene sequences into a linkage map. This will aid in the identification of markers linked to genes of interest and map-based cloning.
\end{abstract}

\section{Background}

Cultivated peanut (Arachis hypogaea L.) originated in South America, and is grown in tropical and sub-tropical regions across 100 countries on six continents between $40^{\circ} \mathrm{N}$ and $40^{\circ} \mathrm{S}$ [1]. Seed dry matter is an important source of digestible protein (25 to $34 \%$ ), cooking oil (44 to $56 \%$ ) and vitamins such as thiamine, riboflavin, and niacin, which are particularly important for human nutrition in many developing countries [2]. As a legume, peanuts

\footnotetext{
* Correspondence: hguohao@mytu.tuskegee.edu

${ }^{3}$ Tuskegee University, Tuskegee, AL 36088, USA

Full list of author information is available at the end of the article
}

improve soil fertility by fixing nitrogen, providing up to 60 $\mathrm{kg} / \mathrm{ha}$ nitrogen to the soil, thus benefiting crops subsequently planted in the same field [3].

Cultivated peanut is a tetraploid $(2 \mathrm{n}=4 \times=40)$, selfpollinating species with a DNA content of about 2813 $\mathrm{Mbp} / 1 \mathrm{C}$ [4]. Very limited genetic variation in peanut has been detected by using molecular markers such as restriction fragment length polymorphisms (RFLPs), isozymes, and random amplified polymorphic DNA (RAPDs) [5-10]. Low genetic diversity among cultivated accessions likely derives from the origin of tetraploid peanut in a single, relatively recent allopolyploid event that is
C Biomed Central

C 2012 Wang et al; licensee BioMed Central Ltd. This is an Open Access article distributed under the terms of the Creative Commons Attribution License (http://creativecommons.org/licenses/by/2.0), which permits unrestricted use, distribution, and reproduction in any medium, provided the original work is properly cited. 
thought to have involved genotypes of the wild diploid species Arachis duranensis and Arachis ipaensis [11-15]. Due to the lack of polymorphism at the DNA level, the crop has not been subject to marker-assisted selection or resistance gene cloning. As a consequence, there is a significant need to pursue genomic strategies in cultivated peanut, with the specific goal of increasing the availability of useful molecular tools.

Importantly, while genetic diversity is low, polymorphisms do exist in numbers that are likely to be sufficient for molecular breeding strategies. The challenges to identifying such polymorphisms involve both scale and data mining: How do we survey a sufficient quantity of the peanut genome to identify large numbers of polymorphisms? One possibility is the use of simple sequence repeat (SSR) markers, which now exist as a set of more than 5,000 assayable loci, many of which are published and show promise as tools for peanut research [16-25].

Genetic linkage maps composed of SSR markers have been constructed for wild diploid genomes (AA [21,24,26] and $\mathrm{BB}$ [27]), as well as for a tetraploid synthetic AABB genome derived from a cross between cultivated and wild amphidiploid species [28]. For these genetic maps it was relatively easy to identify polymorphic markers because the corresponding populations incorporated high rates of polymorphism that are typical of wild Arachis species. More recently, several low resolution linkage maps have been produced for purely cultivated tetraploid AABB genome crosses that harbor much lower polymorphism [29-33]. For these latter linkage maps polymorphic markers were limiting, containing less than 200 SSR markers. However the construction of these genetic maps demonstrates the potential to produce a higher resolution genetic linkage map for cultivated peanut.

Although individual SSR markers could be highly valuable for marker-assisted selection in cases where they are linked to traits of interest, in general the number of polymorphic SSR markers in peanut remains insufficient as a tool for routine genetic analysis. Ideally, plant geneticists and breeders should have access to a sufficient number of polymorphic genetic markers to ensure identification of high value markers that are tightly linked to traits of interest, including disease resistance phenotypes. Therefore, there is a need to expand the density and availability of genetic polymorphisms in peanut, and to survey the status of polymorphic alleles across peanut germplasm.

Bacterial artificial chromosome (BAC) libraries have been constructed for many plant species because they are useful tools for physical mapping, map based cloning, gene structure and function analysis. SSR markers mined from BAC clones (BAC-derived SSR markers) have advantages over other markers without targeted sequence $[34,35]$. BAC-derived SSR markers have been used to facilitate the merging of the genetic and physical maps
$[36,37]$, and have streamlined high resolution mapping and map-based cloning of genes and QTLs of interest [35].

Here we report the identification and characterization of SSRs derived from peanut BAC end sequences (BES). The resulting SSR set is likely to be a good representation of SSRs from the peanut genome as a whole because they were derived from a set of randomly selected BAC sequences. These BES-SSR markers were combined with other publicly available peanut SSR markers to construct a new and higher density genetic linkage map in cultivated peanut, and to initiate the process of integrating physical and genetic map resources in peanut.

\section{Results}

Sequencing and annotation of BAC clone ends

3,784 resistance gene homolog $(\mathrm{RGH})$-containing $\mathrm{BAC}$ clones of $A$. hypogaea cv Tifrunner were identified by means of hybridization with a set of peanut disease resistance gene probes, representing 580 unique nucleotide binding (NB) domains (Rosen, He and Cook unpublished data). These BAC clones were sequenced from their ends to yield 3,905 BAC end sequences (BES) representing 3.5 Mbp of the cultivated Tifrunner genome sequence. Sequencing of an additional 25,000 randomly-selected BAC clones from a library of diploid A. duranensis [38] yielded 32,530 BAC end sequences representing 29.3 Mbp of the A. duranensis genome (Table 1). BAC end sequences were annotated based on a combination of sequence homology using BLAST and comparison to the InterPRO database [39]. BES sequences were divided into five primary categories according to their sequence similarities: (1) putative gene-containing, (2) putative DNA transposable element-containing, (3) putative retroelement-containing, (4) putative organelle- or ribosomal rDNA-containing, and (5) sequences with no detectable similarities, as shown in Table 2. The last of these classes was the largest and represented $48.5 \%$ and $58.0 \%$ in wild and cultivated BACs, respectively. Similar results were obtained for pigeonpea [37], where $53.6 \%$ of BES lacked similiarity to known genes or proteins. BES sequences in the putative gene-containing category represented $44.9 \%$ of total BES in A. duranensis and $38.7 \%$ in $A$. hypogaea. We stress, however, that many BES annotated as "gene-containing" may in fact derive from retroements, due the wide diversity in retroelement sequenes and frequent overlap in annotation vocabularies. There were 4-fold more BES sequences explicitly annotated as retroelements than as DNA transposable elements in both BAC libraries.

\section{Identification and characterization of BES-SSRs}

To enlarge the pool of SSRs in peanut, BES sequences were used for mining SSRs. One hundred twenty eight and 1,296 SSRs were identified from BES sequences in 
Table 1 SSRs identified from BAC end sequences

\begin{tabular}{lcc}
\hline BAC library & A. hypogaea (clones contain RGH) & A. duranensis (random clones) \\
\hline Clones sequenced & 3,784 & 25,000 \\
\hline End sequences & 3,905 & 32,530 \\
\hline BES-SSRs & 128 & 1,296 \\
\hline Primers designed & 105 & 1,047 \\
\hline
\end{tabular}

the cultivated (tetraploid A. hypogaea) and wild (diploid A. duranensis) BAC clones, respectively (Table 2). For both wild and cultivated species, SSRs were more frequent in the non-annotated fraction of BES. As expected, among these SSRs dinucleotide (47.4\%) and trinucleotide (37.1\%) SSRs were predominant (Table 3). Survey of EST-SSRs in peanut [40] revealed a similar trend, with 59.5\% dinucleotide and 33.7\% trinucleotide SSRs. Dinucleotide SSRs composed of AT repeats accounted for $27.4 \%$ of all SSRs, followed by SSRs with AG repeats (15.0\%). For trinucleotide SSRs, the AAG SSRs occurred at slightly higher frequency (15.2\%) than AAT SSRs (12.0\%) (Table 4). Moretzsohn et al. [21] also reported an abundance of AAT SSRs in EST sequences, with only AAG SSRs at a higher frequency. Because AT, AG, AAG, and AAT SSRs represented $67 \%$ of all SSRs in the BES data set, SSRs with these four motifs were compared for their quantity and frequency of polymorphism. For purposes of this analysis, SSRs were further subdivided into two classes based on length (in the sense of Temnykh et al. [41]), with Class I SSRs $\geq$ $20 \mathrm{bp}$ and Class II SSRs $\leq 19 \mathrm{bp}$ in length. For dinucleotide SSRs, the number of SSRs with AT motif in Class I was higher than those in Class II, while SSRs with AG motif were less frequent in Class I than in Class II (Figure 1, Table 5). For trinucleotide SSRs, both SSRs with AAT and AAG motifs in Class II were more frequent than in Class I (Figure 2, Table 6).

A total of 1,152 primer pairs were designed from 128 SSRs related to RGH containing BAC clones of A. hypogaea and 1,296 SSRs mined from the randomly selected BAC clones of A. duranensis. One hundred forty eight (12.8\%) of these 1152 SSR amplicons were polymorphic when compared among eight cultivated genotypes
(Additional file 1). In this analysis we observed similar rates of polymorphism for SSRs identified from A. dura$n e n s i s$ and those identified from the A. hypogaea $(12.9 \%$ and $12.4 \%$, respectively), suggesting that rates of SSR polymorphism do not differ between RGH and non-RGH regions of the genome. These frequencies of polymorphism were consistent with that of publicly available SSRs (10-13\%) $[16,17,19,23,25,29,30]$. The BAC-derived polymorphic SSR markers detected an average of 3.2 alleles per locus, with the polymorphism information content (PIC) values ranging from 0.21 to 0.87 and an average of 0.45 (Additional file 1). The comparison of SSRs in Class I and Class II showed that the frequency of polymorphism was significantly higher in Class I than in Class II for both dinucleotide and trinucleotide SSRs using Fisher's exact test at $P<0.0001$ (Table 5 and 6 ), consistent with previous observations that longer SSRs are more polymorphic [41]. The type of motifs also showed a strong relationship with the frequency of polymorphism. Together, the SSRs with AAT motif generated the greatest frequency (17.5\%) of length polymorphism, followed by SSRs with AT motif (14.5\%), AG motif (10.9\%), and AAG motif (4.5\%). Similar results were obtained for soybean BES-derived SSRs, with AT, AG, and AAT motifs yielding higher rates of length polymorphisms than other motifs [42]. Among this new set of peanut BES-SSRs, those with the highest rates of polymorphism were long SSRs (Class I), with rates of 33.3\% for AG-SSRs, 32.4\% for AAT-SSRs, and 18.2\% for AT-SSRs (Table 5 and 6), making these the most suitable targets for new SSR marker development in cultivated accessions.

Comparison of BES-SSRs identified in this study with publicly available peanut SSRs revealed that $48.7 \%$ of BES-SSRs were identical to SSRs identified previously by

Table 2 Annotation of peanut BAC clone end sequences

\begin{tabular}{|c|c|c|c|c|c|c|c|c|}
\hline & \multicolumn{3}{|c|}{ Genes } & \multirow[t]{2}{*}{$\mathrm{TE}^{\mathrm{a}}$} & \multirow[t]{2}{*}{$\mathrm{RE}^{\mathrm{b}}$} & \multirow[t]{2}{*}{ Organelle/rRNA } & \multirow[t]{2}{*}{ No annotation } & \multirow[t]{2}{*}{ Total } \\
\hline & $\overline{\text { EST }}$ & R-gene & others & & & & & \\
\hline A. duranensis & 5,983 & 92 & 8,536 & 426 & 1,614 & 96 & 15,783 & 32,530 \\
\hline A. hypogaea & 621 & 50 & 842 & 16 & 79 & 32 & 2,265 & 3,905 \\
\hline Total & 6,604 & 142 & 9,378 & 442 & 1,693 & 128 & 18,050 & 36,435 \\
\hline \multicolumn{9}{|c|}{ SSRs mined from A. duranensis and A. hypogaea } \\
\hline SSRs in Ad & 108 & 2 & 302 & 5 & 19 & 3 & 857 & 1,296 \\
\hline SSRs in Ah & 15 & 5 & 26 & & & & 82 & 128 \\
\hline
\end{tabular}

${ }^{\mathrm{a}}$ Transposable element; ${ }^{\mathrm{b}}$ Retroelement 
Table 3 Percentage of each type of motifs in peanut genome

\begin{tabular}{lcc}
\hline Repeat motif & Genomic SSR (\%) & EST-SSR $^{*}$ (\%) \\
\hline Dinucleotide & 47.4 & 59.5 \\
\hline Trinucleotide & 37.1 & 33.7 \\
\hline Tetranucleotide & 4.3 & 1.6 \\
\hline Pentanucleotide & 1.4 & 0.2 \\
\hline Hexanucleotide & 0.5 & 0.3 \\
\hline Compound & 9.3 & 4.5 \\
\hline Total SSRs & 1,424 & 593 \\
\hline
\end{tabular}

*cited from Guo et al. 2009

other means (see columns I \& J in Additional file 1). Not surprisingly, there was less overlap in the identity of $23 \%$ primer sequences for PCR (column K \& L in Additional file 1), and thus the current data set provides both novel SSRs and novel primer sets for a portion of previously discovered SSRS.

\section{Mapping of BES-SSRs}

The BES-SSRs developed in this study and $\sim 4,000$ SSRs publicly available were evaluated for their genetic polymorphism between two parental genotypes Tifrunner and GT-C20. A total of 347 polymorphic DNA markers, including 68 BES-SSR markers, 7 target region amplification polymorphism (TRAP) markers, and 1 sequence tagged site (STS) marker, were identified and used to detect 385 segregating loci. Detailed information on mapped SSR primer sequences and motifs are given in Additional file 2. Among 347 polymorphic markers, 35 identified 2 independently segregating loci and 1 generated 3 independently segregating loci. These multi-locus SSRs are designated using the suffixes " -1 " and "- 2 " after the locus name, for 2 and 3 independent loci, respectively.

Table 4 Frequency of individual SSR motifs

\begin{tabular}{lcc}
\hline Repeat motif & Number of SSRs & Frequency (\%) \\
\hline AT/TA & 390 & 27.4 \\
\hline AG/GA/CT/TC & 214 & 15.0 \\
\hline AC/CA/TG/GT & 68 & 4.8 \\
\hline GC/CG & 18 & 1.3 \\
\hline AAG/AGA/GAA/CTT/TTC/TCT & 217 & 15.2 \\
\hline AAT/ATA/TAA/TT/TTA/TAT & 171 & 12.0 \\
\hline ATG/TGA/GAT/CAT/ATC/TCA & 49 & 3.4 \\
\hline AAC/ACA/CAA/GTT/TTG/TGT & 36 & 2.5 \\
\hline ACC/CCA/CAC/GGT/GTG/TGG & 21 & 1.5 \\
\hline AGG/GGA/GAG/CCT/CTC/TCC & 18 & 1.3 \\
\hline AGT/GTA/TAG/ACT/CTA/TAC & 13 & 0.9 \\
\hline AGC/GCA/CAG/GCT/CTG/TGC & 8 & 0.6 \\
\hline ACG/CGA/GAC/CGT/GTC/TCG & 4 & 0.3 \\
\hline GGC/GCG/CGG/GCC/CCG/CGC & 3 & 0.2 \\
\hline
\end{tabular}

Chi-square $\left(\chi^{2}\right)$ analysis identified 128 (32.3\%) loci that deviated from the expected 1:2:1 or 3:1 segregation ratio at $P>0.05$ level. Using a LOD score of 4 with the JoinMap4 software, 333 loci were mapped. Twenty-one LGs contained 318 loci that encompassed 1,674.4 cM of total map distance (Figure 3), while an additional 7 linkage groups contained 3 or fewer loci, for a total of 18 markers. The size of the 21 largest linkage groups ranged from $40.2 \mathrm{cM}$ (12 loci) to $124 \mathrm{cM}$ (26 loci), with an average distance of $5.3 \mathrm{cM}$ between adjacent loci. Among the mapped loci, 71 (22.3\%) were BAC-derived SSRs distributed among all but 5 of 21 linkage groups, i.e. LG2, LG13, LG14, LG16, and LG17 (Figure 3). Two markers (GNB1076 and GNB1112) from BAC-derived SSRs related to RGH were mapped to two different groups (LG10 and 18), and anchored 1 $\mathrm{RGH}-\mathrm{BAC}$ contig containing $7 \mathrm{BAC}$ clones and 1 singleton to this genetic linkage map.

\section{Discussion}

BAC end sequences have been shown to be a powerful tool for developing molecular markers. BAC-derived markers can be used to integrate physical maps with genetic maps $[36,43]$, and also facilitate map-based cloning [44,45]. About $32.8 \mathrm{Mbp}$ of peanut genomic sequences obtained from BAC end sequences was used for mining of SSR markers in this study. We also report a detailed analysis of these BAC derived SSR. Surprisingly, a large proportion of BES possess similarity to gene sequences (44.9\% of the wild $A$. duranensis BES and $38.7 \%$ of the cultivated A. hypogaea BES), though we note that a significant fraction of these gene-containing BES may derive from retroelements. SSR frequency was 44.2 and $36.6 \mathrm{SSR} / \mathrm{Mbp}$ in wild and cultivated BAC clones, respectively. These differences may reflect differences between the genomes of the cultivated tetraploid genome and the wild diploid genome, but perhaps more likely reflect differences in the nature of the BAC clones (i.e., enriched for disease resistance genes in the case of $A$. hypogaea and randomly selected clones in the case of A. duranensis) or differences in the construction methods of the two BAC libraries (random-shear and partial HindIII cleavage, respectively).

Allelic diversity estimated for 148 BES derived SSR polymorphic markers was an average of 3.2 alleles per locus, and ranged from 2 to 8 alleles at each locus based on eight genotypes tested. This level of allelic diversity is lower than that reported in previous studies, including allele of 3 to 19 (mean 6.9) for 48 Valencia genotypes, 2 to 27 (mean 8.4) for 60 Brazilian genotypes [20], and 2 to 20 (mean 10.1) among 141 genotypes from the US mini core collection and wild species. However, Cuc et al. (2008) reported allele numbers ranging from 2 to 5 with a mean of 2.44 in 32 genotypes [23]. Although allelic diversity can be used as an indicator of genetic variation, such values are relative 


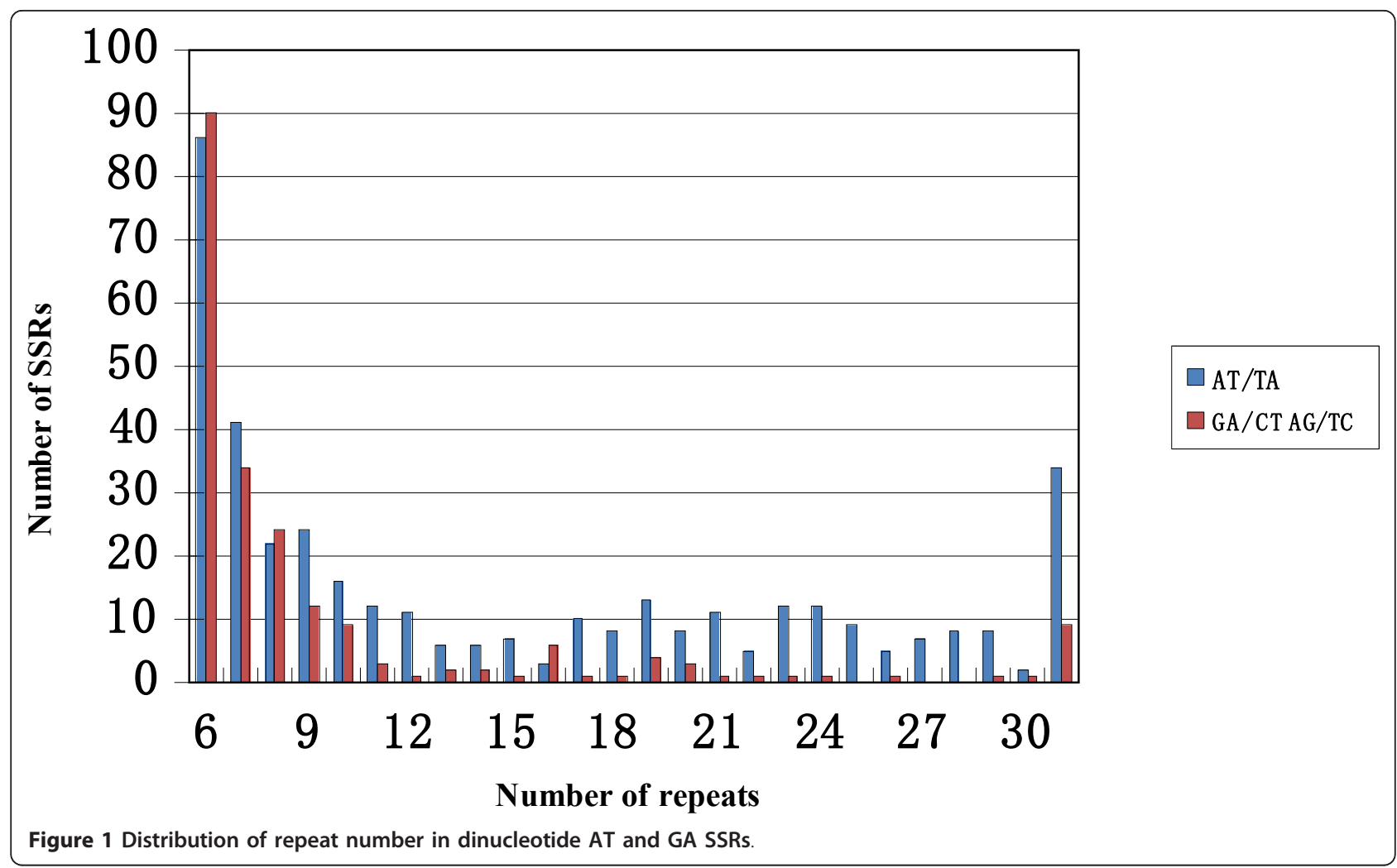

and depend on the number of polymorphic loci and the relatedness of genotypes analyzed. In this study, only 8 genotypes were used, all representing cultivated materials, both of which set upper ranges on the number of polymorphic loci that could be identified.

Much publicly available SSR data has been derived from AG repeat motif sequences using enrichment methods involving hybridization to SSR probes $[17,19,23]$. The use of AT sequences in such procedures is generally avoided because of the potential for the probe to form a hairpin structure, and thus to function inefficiently. Interestingly the current analysis of BES derived SSRs found that SSRs with AT motifs were the most frequent. The randomly selected BAC clones used for developing SSR markers most likely are a good representation of the diploid peanut genome, and thus the distributions and

Table 5 Polymorphism rates of dinucleotide AT and AG SSRs in two classes

\begin{tabular}{llccc}
\hline Number of repeat & Non-polymorphic & polymorphic & Total \\
\hline$>10$ (Class I) & AT-SSRs & $175(81.8 \%)$ & $39(18.2 \%)$ & 265 \\
\cline { 2 - 5 } & AG-SSRs & $34(66.7 \%)$ & $17(33.3 \%)$ & \\
\hline $6-9$ (Class II) & AT-SSRs & $156(90.2 \%)$ & $17(9.8 \%)$ & 333 \\
\cline { 2 - 5 } & AG-SSRs & $154(96.2 \%)$ & $6(3.8 \%)$ & \\
\hline Total dinucleotide SSRs & $519(86.8 \%)$ & $79(13.2 \%)$ & 598 \\
\hline
\end{tabular}

frequencies of the SSRs identified in this study are likely to be a good reflection of their genome-wide frequencies. Comparison of polymorphism rates among AT SSRs and AG SSRs shows that the former has a somewhat higher polymorphism rate than the latter (Table 5). For trinucleotide SSRs, polymorphism of the AAT SSRs is 3.2-fold higher than the polymorphism rate of AAG SSRs (Table 6). This result suggests that AT-rich SSR loci may have relatively high variability in peanut. Several studies have reported that SSRs with larger numbers of repeats have correspondingly higher rates of polymorphism $[21,36,46]$. Temnykh et al. [41] have suggested that SSRs could be divided into two classes: Class I were long and hypervariable markers, and Class II were short and typically less variable markers. The mutation rate of SSRs increases with repeat number, but long SSRs in eukaryotic genomes have a mutation bias to become shorter SSRs [47]. Our data also showed that both dinucleotide and trinucleotide SSRs in Class I detected more polymorphism than those in Class II. The finding suggested that it is worth developing markers based on long AT-rich SSRs to provide new informative SSR markers in peanut.

In peanut, several efforts have been made to construct genetic linkage maps and to meet the pre-requisites for marker-assisted selection in breeding and map-based cloning of desirable genes. The first genetic linkage map in peanut was constructed by Halward et al. [48] in an F2 


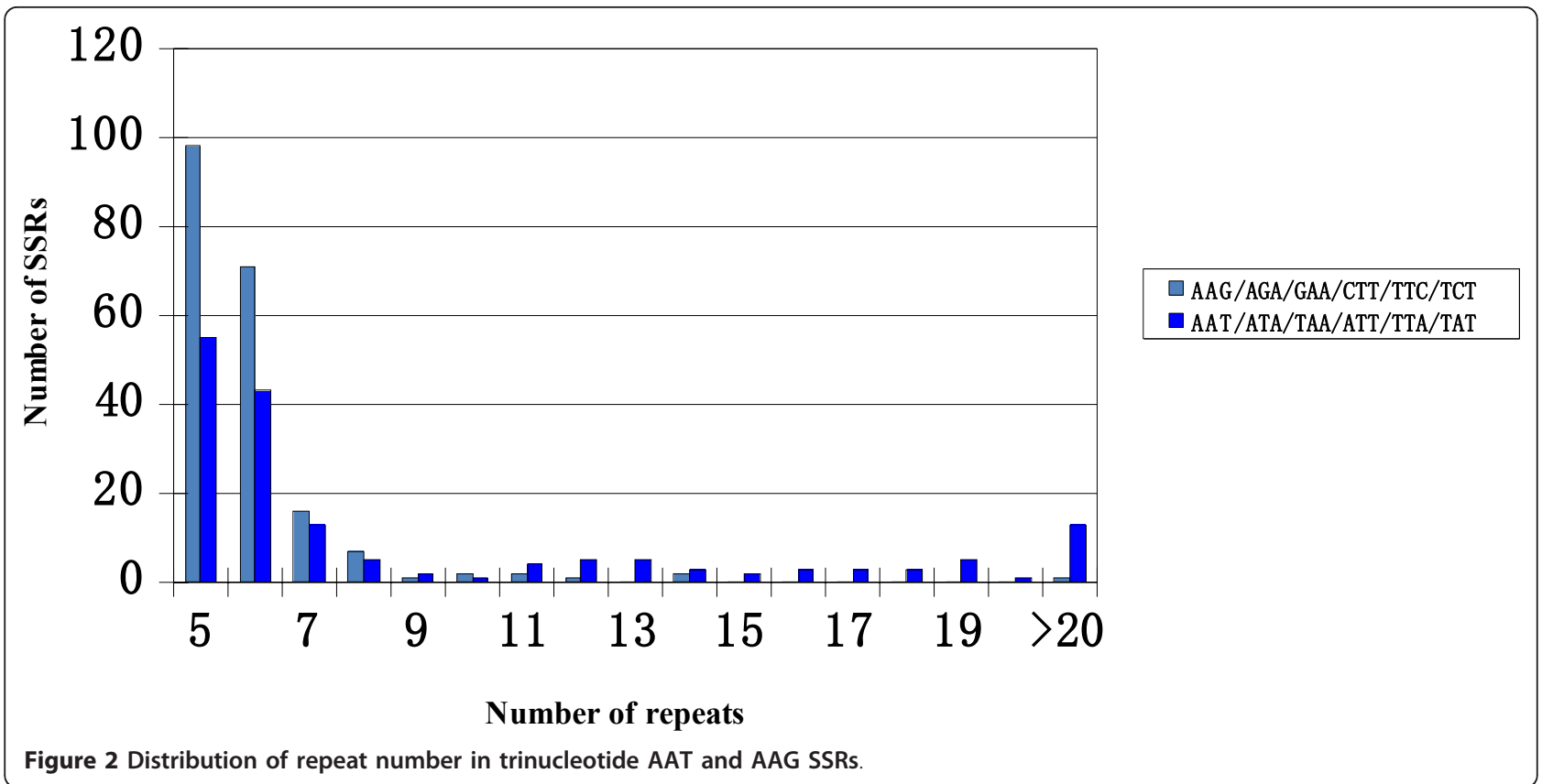

population derived from a cross between two diploid wild species $A$. stenosperma and A. cardenasii using RFLP markers. Another RFLP-based map was developed from a $\mathrm{BC} 1$ tetraploid population of a synthetic amphidiploid A. batizocoi x (A. cardenasii x A. diogoi) crossed with cv. Florunner [49]. However, insufficient variability detected by RFLPs or RAPDs within $A$. hypogaea germplasm has hindered the construction of a genetic linkage map directly in cultivated peanut [48]. As more SSRs have been developed during the past decade, several SSRbased maps have been constructed, including AA genome and BB genome maps in wild $\mathrm{x}$ wild species populations $[21,24,26,27]$, and some genetic maps in cultivated $\mathrm{x}$ cultivated populations [29-33]. These cultivated maps contain only $\sim 200$ SSR loci and thus require additional markers if they are to have utility for peanut breeding. The genetic map constructed by Hong et al. (2010) consisted of 175 SSR loci with a total coverage of $885.4 \mathrm{cM}$ [50], this map was a consensus constructed using three cultivated $x$ cultivated mapping populations. In this study, a large number of BES-SSRs were incorporated into a cultivated genetic map, increasing the number of

Table 6 Polymorphism rates of trinucleotide AAT and AAG SSRs in two classes

\begin{tabular}{llccc}
\hline Number of repeat & Non-polymorphic & polymorphic & Total \\
\hline$>7$ (Class I) & AAT-SSRs & $46(67.6 \%)$ & $22(32.4 \%)$ & 100 \\
\cline { 2 - 5 } & AAG-SSRs & $29(90.6 \%)$ & $3(9.4 \%)$ & \\
\hline $5-6$ (Class II) & AAT-SSRs & $91(92.9 \%)$ & $7(7.1 \%)$ & 267 \\
\cline { 2 - 5 } & AAG-SSRs & $163(96.4 \%)$ & $6(3.6 \%)$ & \\
\hline Total trinucleotide SSRs & $329(89.6 \%)$ & $38(10.4 \%)$ & 367 \\
\hline
\end{tabular}

mapped markers to 318 in a single cultivated mapping population, enlarging the coverage to $1,674 \mathrm{cM}$, and reducing average distance between two adjacent markers to $5.3 \mathrm{cM}$. However, there were seven groups containing only 3 or fewer loci and 49 loci could not be mapped, indicating that the linkage map remains incomplete.

The use of common markers between the present map and previous maps allows a comparison of recombination frequency and marker order among mapping populations. Five linkage groups in the present map were chosen to compare with the first SSR-based peanut map [30], because there were several markers incommon between two maps (Figure 4). Comparison of these two maps reveals both conservation of marker order and rearranged order the between two populations. For instance, LG7 and LG10 in present map had the same marker order as LG_AhIII and LG_AhVI in previous map. Three other linkage groups, however, revealed rearrangements in marker order between two mapping populations (Figure 4).

Ten percent of polymorphic SSRs surveyed more than one genetic locus. This situation, which has been noted previously by other authors [30,32], is presumed to derive from the high similarity of the two subgenomes of tetraploid A. hypogaea. In this study, most (82\%) of the SSRs that amplified more than one locus were long SSRs (> $30 \mathrm{bp}$ ) or compound SSRs. Strachan and Read (1999) reported that SSRs with high repeat numbers are unstable during mitosis and meiosis in humans [51], and as a consequence are highly variable. By analogy, long SSRs are more likely to reveal distinct polymorphisms in the two subgenomes of allotetraploid peanut. 


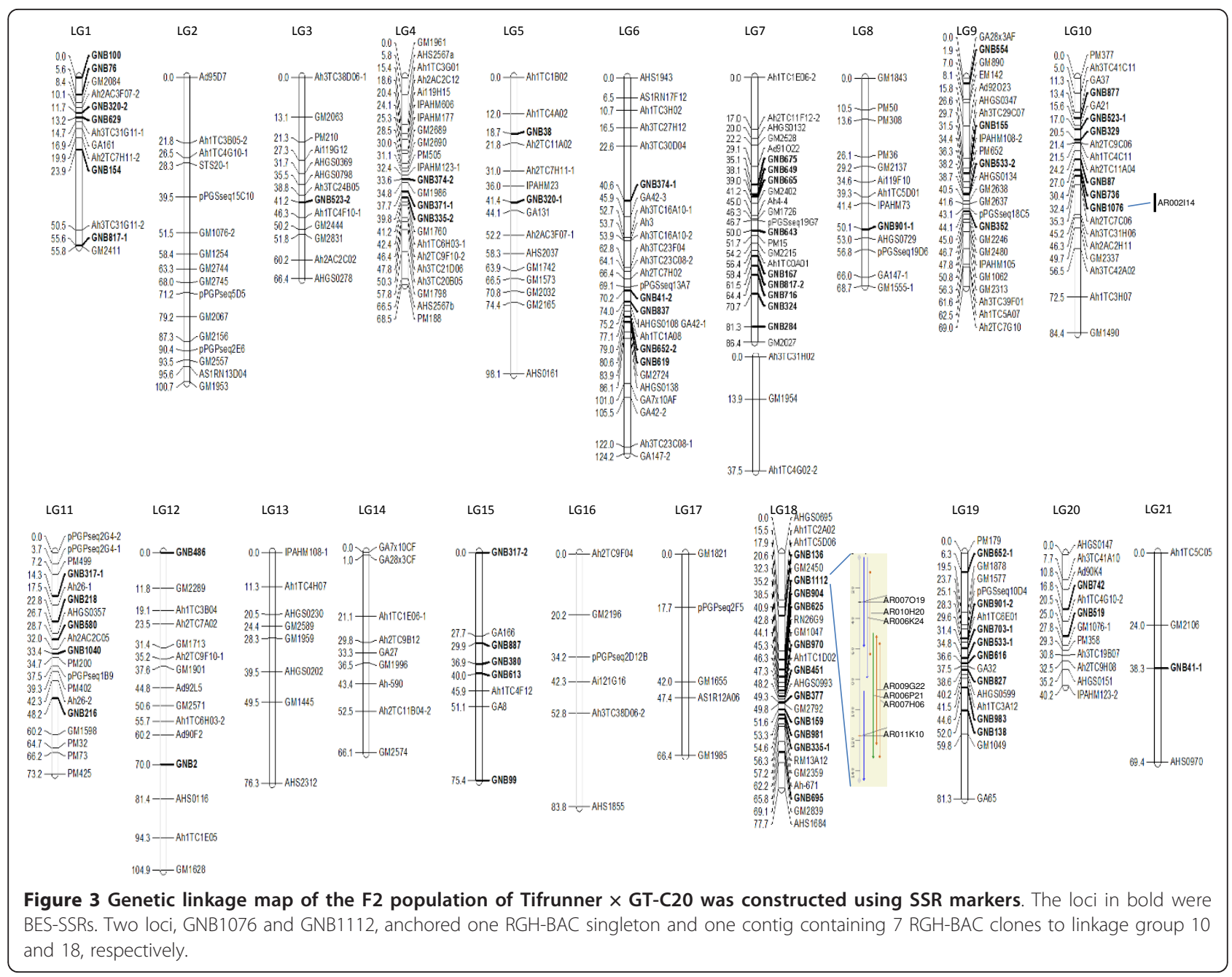

In parallel to the analysis of BAC-derived SSR markers, we have also used the TRAP marker technique to determine the potential application in peanut. Only seven $(\sim 2 \%)$ out of 400 TRAP primer pairs were polymorphic and were placed on the linkage map. This indicates that TRAP markers, the generation of which involves the use of arbitrary primers, have only a low chance of detecting polymorphism in the narrow genetic base in peanut.

One advantage of using BAC-derived markers in genetic linkage map construction is that physical contigs can be anchored on genetic map by mapping BAC-derived markers [37]. The integrated map would be useful in markerassisted selection to introgress genes of interest into elite cultivars when BAC-derived markers reside in these genes, and would facilitate map-based cloning of genes and QTLs. In this study, 105 BAC-derived SSRs related to RGH-based physical contigs and singletons were developed. Only three of these SSRs were polymorphic between the two parents; two of these SSRs were mapped, thus anchoring 1 contig and 1 singleton into the current genetic map. The other marker, related to one RGH contig consisting of three clones was unmapped. Genetic linkage of candidate gene BAC contigs with phenotypes should enhance the opportunity for targeted marker development. In particular, the sequences of the BAC clones can provide the substrate for new marker development. Although we have mapped only a small number of RGH-containing BAC clones in this work, we have identified BAC contigs that contain the vast majority of $\sim 580$ peanut NBS-LRR RGH sequences (Rosen, He and Cook, unpublished data). Targeted marker development from these BAC clones holds potential to enhance the current peanut SSR framework with a large number of high value disease resistance candidate genes, and thus define the landscape of R-genes in peanut genome.

\section{Conclusion}

The SSRs mined from BAC end sequences of randomly selected clones and RGH containing clones in this study 


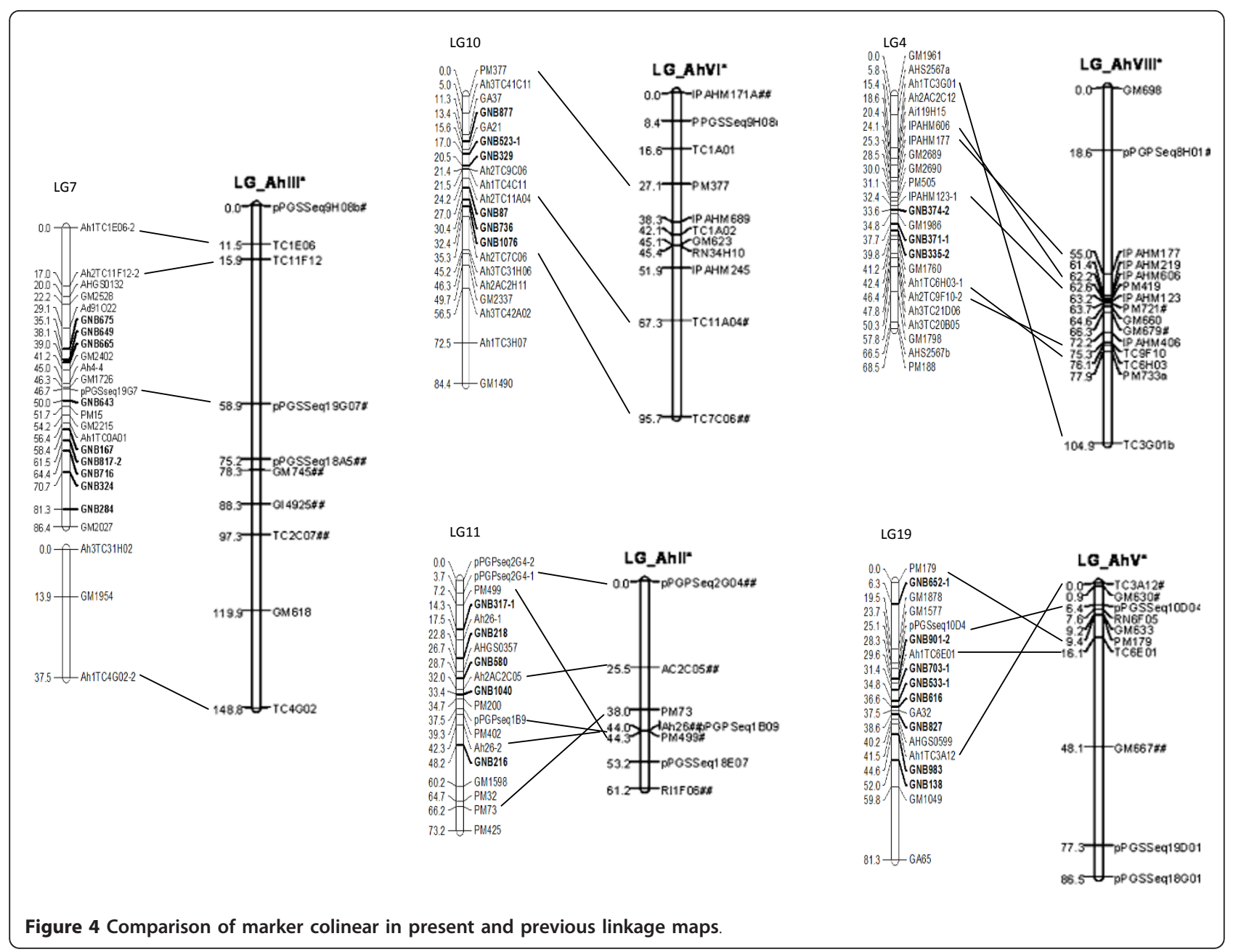

enlarge the pool of informative SSR markers in peanut. These new SSR markers provide useful genetic and genomic tools for molecular analysis of peanut genome, and facilitate the construction of higher density genetic linkage maps. In addition, SSR markers related to RGHs provide a valuable resource for incorporating RGH contigs and singletons into genetic map, which will ultimately increase our understanding of the distribution and organization of disease resistance genes in the peanut genome. Such information will facilitate markerassisted selection for disease resistance breeding and map-based cloning of resistance genes.

\section{Methods}

\section{Sequencing of BAC clone ends}

To identify BAC clones which harbored RGHs, we used a BAC library representing an estimated $6 \mathrm{x}$ of the genome of peanut cv. Tifrunner together with 589 unique RGH sequences isolated from the genome of Tifrunner (unpublished results). Based on comparison to the sequenced genomes of Medicago truncatula and Glycine $\max$, these 589 RGHs represent the vast majority of resistance gene homologs in peanut genome. Hybridization of the BAC library with a representative set of RGH sequence probes yielded a set of 3,784 BAC clones. These $\mathrm{RGH}$ containing BAC clones were assembled using high information content fingerprinting (HICF) [52], and resulted in 344 contigs and 334 singleton loci, for a total of 678 resistance gene regions in the peanut genome. All these 3,784 RGH containing BAC clones were used for end sequencing. In addition, 25,000 clones randomly selected from a BAC library from the wild species $A$. duranensis [38] were end sequenced. The BESs were subjected to a homology search for annotation by BLAST.

\section{Identification of SSRs from BES and primer designing}

After removing short or redundant sequences, BES sequences were used for mining SSRs using the MISA search module [53,54]. SSRs were identified using cutoff values of six repeats for dinucleotide, five repeats for trinucleotide, and four repeats for tetranucleotide SSRs. 
Based on length of SSRs and their potential as informative DNA markers, the identified SSRs were classified into two groups: Class I consisted of SSRs $\geq 20 \mathrm{bp}$, and Class II consisted of SSRs $\geq 12$ bp $<20$ bp [37,41]. Primers were designed to flank the SSR sequence and generate a PCR fragment between 150 and 300 bp. Primers were designed using the Primer3 software [55]. The designed primers were screened for polymorphism against eight cultivated genotypes, Tifrunner, GT-C20, SunOlic 97R, NC94022, D99, H22, Yue you 92, and Xin Hui Xiao Li, the first four of which being US peanut cultivars and the latter four Chinese cultivars or breeding lines. The informative SSRs were measured by PIC value [56].

\section{Construction of a mapping population}

The $\mathrm{F}_{2}$ mapping population was constructed at USDAARS, Coastal Plain Experimental Station at Tifton, Georgia using cv. Tifrunner and GT-C20 as parents. Tifrunner is a runner market-type cultivar with a high level of resistance to TSWV, and moderate resistance to early (Cercospora arachidicola) and late leaf spot (Cercosporidium personatum), but it is a late maturity cultivar [57]. GT-C20 is a Spanish-type breeding line and highly susceptible to TSWV and leaf spots but resistant to aflatoxin contamination [58]. Young leaves were taken from parents and $94 \mathrm{~F}_{2}$ individual plants for DNA isolation using a modified CTAB method [59].

\section{Mapping of BES-SSRs}

The polymorphic SSRs identified from BAC end sequences were used for construction of genetic linkage map. PCR was performed in a total volume of $10 \mu \mathrm{l}$ of a reaction mixture containing $25 \mathrm{ng}$ genomic DNA, 200 $\mu \mathrm{M}$ each dNTP, $0.1 \mu \mathrm{M}$ each of forward primer with M13-tail and reverse primer, $0.1 \mu \mathrm{M}$ M13 primer labelled by 700 - or 800 -IR dye (LI-COR Biosciences, $\mathrm{NE}), 1 \times$ reaction buffer $\left(10 \mathrm{mM} \mathrm{KCl,10} \mathrm{mM}\left(\mathrm{NH}_{4}\right)\right.$ ${ }_{2} \mathrm{SO}_{4}, 20 \mathrm{mM}$ Tris- $\mathrm{HCl}, 2 \mathrm{mM} \mathrm{MgSO} 4,0.1 \%$ Triton $\mathrm{X}-$ 100), and 0.25 U Taq DNA polymerase (BioLabs, Beverly, MA). Amplifications were performed using a DNA Engine Dyad (BioRad, CA) thermal cycler, with the following cycling conditions: an initial $5 \mathrm{~min}$ at $95^{\circ} \mathrm{C} ; 35$ cycles of $30 \mathrm{~s}$ at $94^{\circ} \mathrm{C}, 30 \mathrm{~s}$ at $55^{\circ} \mathrm{C}$, and $30 \mathrm{~s}$ at $72^{\circ} \mathrm{C}$; and a final $3 \mathrm{~min} 72^{\circ} \mathrm{C}$. Amplicons were analyzed by LICOR DNA analyzer (LI-COR Biosciences, NE). In addition, we have evaluated the feasibility of TRAP [60] markers using sequence related amplified polymorphism (SRAP) [61] primer paired with RGH primer to detect a polymorphism in peanut. Four hundred such primer pairs were screened. PCR reaction mixture included 25 ng genomic DNA, $200 \mu \mathrm{M}$ each dNTP, $0.375 \mu \mathrm{M}$ each primer, $1 \times$ reaction buffer, and $0.2 \mathrm{U}$ Taq DNA polymerase (BioLabs, Beverly, MA) in $10 \mu \mathrm{l}$. PCR condition was following the protocol of $\mathrm{Hu}$ and Vick [60]. The polymorphic BAC-derived SSR markers and TRAP markers combined with polymorphic SSRs from other public resources were used for mapping. Marker order and map distances were determined by JoinMap4 software (Kyazma, Netherlands) with the Kosambi map function [62].

\section{Additional material}

Additional file 1: List of BES-SSRs.

Additional file 2: List of mapped SSRs in the F2 mapping

population of Tifrunner $\times$ GT-C20

\section{Acknowledgements}

Authors are thankful to National Science Foundation (NSF, DBI-0605251) and USDA/CSREES/Capacity Building Program (\#2006-38814-17489) for supporting this research.

\section{Author details}

'Shandong Peanut Research Institute, Qingdao, China. ${ }^{2}$ University of California, Davis, CA 95616, USA. ${ }^{3}$ Tuskegee University, Tuskegee, AL 36088, USA. ${ }^{4}$ Fujian Agricultural and Forestry University, Fuzhou, China. ${ }^{5}$ USDA-ARS, Tifton, GA 31793, USA. ${ }^{6}$ National Center of Genome Resources (NCGR), Santa Fe, NM 87505, USA. ${ }^{7}$ Kazusa DNA Research Institute, Chiba, Japan. ${ }^{8}$ University of Brasilia, Brasilia, Brazil. ${ }^{9}$ Intenational Crops Research Institute for the SemiArid Tropics (ICRISAT), Patancheru, India.

\section{Authors' contributions}

$H W, L G, Y M$, and $Y Z$ carried out genotyping and genetic linkage mapping. YM and JG conducted hybridization of BAC library with RGH probes, which were provided by BDR. RVP, ADF, and GH carried out SSR mining, primer designing, sequence annotation, and data analysis for BES-SSRs. BZ, SI, DJB, and RKV provided their developed SSRs. BZ established the mapping population and provided plant materials. DRC conceived the study, designed experiments and coordinated the study. RVP, DJB, RKV, DRC and $\mathrm{GH}$ participated in drafting the manuscript. $\mathrm{GH}$ finalized the manuscript. All authors read manuscript.

Received: 11 May 2011 Accepted: 19 January 2012

Published: 19 January 2012

\section{References}

1. Naidu RA, Kimmins FM, Deom CM, Subrahmanyam P, Chiyembekeza AJ, van der Merwe PJA: Groundnut rosette: a virus disease affecting groundnut production in sub-Saharan Africa. Plant Dis 1999, 83:700-709.

2. Savage GP, Keenan Jl: The composition and nutritive value of groundnut kernels. In The Groundnut Crop: A Scientific Basis for Improvement. Edited by: Smartt J. London: Chapman 1994:173-213.

3. Sprent J: Nitrogen fixation. In The Groundnut Crop A Scientific Basis for Improvement. Edited by: Smartt J. London: Chapman 1994 .

4. Arumuganatham, Earle : Nuclear DNA content of some important plant species. Plant Mol Biol Rep 1991, 9:211-215.

5. Kochert G, Halward T, Branch WD, Simpson CE: RFLP variability in peanut (Arachis hypogaea L.) cultivars and wild species. Theor App/ Genet 1991, 81:565-570.

6. Halward TM, Stalker HT, Larue EA, Kochert G: Genetic variation detectable with molecular markers among unadapted germplasm resources of cultivated peanut and related wild species. Genome 1991, 34:1013-1020.

7. Halward TM, Stalker HT, LaRue E, Kochert G: Use of single-primer DNA amplification in genetic studies of peanut (Arachis hypogaea L.). Plant Mol Biol 1992, 18:315-325.

8. Paik-Ro OG, Smith RL, Knauft DA: Restriction fragment length polymorphism evaluation of six peanut species within the Arachis section. Theor Appl Genet 1992, 84:201-208. 
9. Stalker HT, Phillips TD, Murphy JP, Jones TM: Variation of isozyme patterns among Arachis species. Theor Appl Genet 1994, 87:746-755.

10. Subramanian V, Gurtu S, Rao RCN, Nigam SN: Identification of DNA polymorphism in cultivated groundnut using random amplified polymorphic DNA (RAPD) assay. Genome 2000, 43(4):656-660.

11. Kochert G, Stalker HT, Gimenes M, Galgaro L, Lopes CR, Moore K: RFLP and cytogenetic evidence on the origin and evolution of allotetraploid domesticated peanut, Arachis hypogaea (Leguminosae). Am J Bot 1996, 83:1282-1291.

12. Seijo JG, Lavia GL, Fernandez A, Krapovickas A, Ducasse D, Moscone EA: Physical mapping of the $5 \mathrm{~S}$ and $18 \mathrm{~S}-25 \mathrm{~S}$ rRNA genes by FISH as evidence that Arachis duranensis and $A$. ipaensis are the wild diploid progenitors of A. hypogaea (Leguminosae). Am J Bot 2004, 9:1294-1303.

13. Seijo GJ, Lavia Gl, Fernandez A, Krapovickas A, Ducasse D, Bertioli DJ, Moscone DEA: Genomic relationships between the cultivated peanut (Arachis hypogaea - Leguminosae) and its close relatives revealed by double GISH. Am J Bot 2007, 94:1963-1971.

14. Favero AP, Simpson CE, Valls JFM, Vello NA: Study of the evolution of cultivated peanut through crossability studies among Arachis ipaensis, $A$. duranensis, and A. hypogaea. Crop Sci 2006, 46:1546-1552.

15. Burow MD, Simpson CE, Faries MW, Starr JL, Paterson AH: Molecular biogeographic study of recently described B- and A-genome Arachis species, also providing new insights into the origins of cultivated peanut. Genome 2009, 52:107-119.

16. Hopkins MS, Casa AM, Wang T, Mitchell SE, Dean RE, Kochert GD, Kresovich S: Discovery and characterization of polymorphic simple sequence repeats (SSRs) in peanut. Crop Sci 1999, 39:1243-1247.

17. He GH, Meng RH, Newman M, Gao GQ, Pittman RN, Prakash CS: Microsatellites as DNA markers in cultivated peanut (Arachis hypogaea L.). BMC Plant Biol 2003, 3:3.

18. He GH, Meng RH, Gao H, Guo B, Gao G, Newman M, Pittman RN, Prakash CS: Simple sequence repeat markers for botanical varieties of cultivated peanut (Arachis hypogaea L.). Euphytica 2005, 142:131-136

19. Ferguson ME, Burow MD, Schulze SR, Bramel PJ, Paterson AH, Kresovich S, Mitchell S: Microsatellite identification and characterization in peanut ( $A$. hypogaea L.). Theor Appl Genet 2004, 108:1064-1070.

20. Moretzsohn MC, Hopkins MS, Mitchell SE, Kresovich S, Valls JFM, Ferreira ME: Genetic diversity of peanut (Arachis hypogaea L.) and its wild relatives based on the analysis of hypervariable regions of the genome. $B M C$ Plant Biol 2004, 4:11

21. Moretzsohn MC, Leoi L, Proite K, Guimaraes PM, Leal-Bertioli SCM, Gimenes MA, Martins WS, Valls JFM, Grattapaglia D, Bertioli DJ: A microsatellite-based, gene-rich linkage map for the AA genome of Arachis (Fabaceae). Theor Appl Genet 2005, 111(6):1060-1071.

22. Proite K, Leal-Bertioli SCM, Bertioli DJ, Moretzsohn MC, da Silva FR, Martins NF, Guimaraes PM: ESTs from a wild Arachis species for gene discovery and marker development. BMC Plant Biol 2007, 7:7.

23. Cuc LM, Mace ES, Crouch JH, Quang VD, Long TD, Varshney RK: Isolation and characterization of novel microsatellite markers and their application for diversity assessment in cultivated groundnut (Arachis hypogaea L.). BMC Plant Biol 2008, 8:55.

24. Leal-Bertioli SCM, Jose Ana CVF, Freitas Dione MTA, Moretzsohn MC Guimaraes PM, Nielen S, Vidigal BS, Pereira RW, Pike J, Favero AP, Parniske M, Varshney RK, Bertioli DJ: Identification of candidate genome regions controlling disease resistance in Arachis. BMC Plant Biol 2009, 9:112.

25. Gautami B, Ravi K, Lakshmi NM, Hoisington DA, Varshney RK: Novel set of groundnut SSRs for genetic diversity and interspecific transferability. Int J Integr Biol 2009, 7:100-106.

26. Bertioli D, Moretzsohn M, Madsen LH, Sandal N, Leal-Bertioli S, Guimarães P, Hougaard BK, Fredslund J, Schauser L, Nielsen AM, Sato S, Tabata S, Cannon S, Stougaard J: An analysis of synteny of Arachis with Lotus and Medicago sheds new light on the structure, stability and evolution of legume genomes. BMC Genomics 2009, 10:45.

27. Moretzsohn MC, Barbosa AVG, Alves-freitas DMT, Teizeira C, LealBertioli SCM, Guimaraes PM, Pereira RW, Lopes CR, Cavallari MM, Valls JFM, Bertioli DJ, Gimenes MA: A linkage map for the B-genome of Arachis (Fabaceae) and its synteny to the A-genome. BMC Plant Biol 2009, 9:40.

28. Fonceka D, Hodo-Abalo T, Rivallan R, Faye I, Ndoye M, Ndoye O, Favero AP, Bertioli DJ, Glaszmann JC, Courtois B, Rami JF: Genetic mapping of wild introgressions into cultivated peanut: a way toward enlarging the genetic basis of a recent allotetraploid. BMC Plant Biol 2009, 9:103.

29. Hong YB, Liang XQ, Chen XP, Liu HY, Zhou GY, Li SX, Wen SJ: Construction of genetic linkage map based on SSR markers in peanut (Arachis hypogaea L.). Agric Sci in China 2008, 7(8):915-921.

30. Varshney RK, Bertioli DJ, Moretzsohn MC, Vadez V, Krishramurthy L, Aruma R, Nigam SN, Moss BJ, Seetha K, Ravi K, He GH, Knapp SJ, Hoisington DA: The first SSR-based genetic linkage map for cultivated groundnut (Arachis hypogaea L.). Theor Appl Genet 2009, 118(4):729-39.

31. Khedikar YP, Gowda MVC, Sarvamangala C, Patgar KV, Upadhyaya HD, Varshney RK: A QTL study on late leaf spot and rust revealed one major QTL for molecular breeding for rust resistance in groundnut (Arachis hypogaea L.). Theor Appl Genet 2010, 121:971-984.

32. Ravi K, Vadez V, Isobe S, Mir RR, Guo Y, Nigam SN, Gowda MVC Radhakrishnan T, Bertioli DJ, Knapp SJ, Varshney RK: Identification of several small main-effect QTLs and a large number of epistatic QTLs for drought tolerance related traits in groundnut (Arachis hypogaea L.). Theor Appl Genet 2011, 122:1119-1132.

33. Sarvamangala C, Gowda MVC, Varshney RK: Identification of quantitative trait loci for protein content, oil content and oil quality for groundnut (Arachis hypogaea L.). Field Crops Res 2011, doi:10.1016/j.fcr.2011.02.010.

34. Yu JZ, Kohel RJ, Dong J: Development of integrative SSR markers from TM-1 BACs. Proceeding of Beltwide Cotton Improvement Conference Atlanta: CD-Rom Published by National Cotton Council of America; 2002, January 812.

35. Guo Y, Sukumar S, Yu JZ, Jenkins JN, Kohel RJ, Scheffler BE, Stelly DM: BACderived SSR markers chromosome locations in cotton. Euphytica 2008, 161:361-370.

36. Mun JH, Kim DJ, Choi HK, Gish J, Debelle F, Mudge J, Denny R, Endre G, Saurat O, Dudez AM, Kiss GB, Roe B, Young ND, Cook DR: Distribution of microsatellites in the genome of Medicago truncatula: a resource of genetic markers that integrate genetic and physical maps. Genetics 2006, 172:2541-2555

37. Bohra A, Dubey A, Saxena RK, Penmetsa RV, Poornima KN, Kumar N, Framer AD, Srivani G, Upadhyaya HD, Gothalwal R, Ramesh S, Singh D, Saxena K, Kavikishor PB, Singh NK, Town CD, May GD, Cook DR, Varshney RK: Analysis of BAC-end sequences (BESs) and development of BES-SSR markers for genetic mapping and hybrid purity assessment in pigeonpea (Cajanus spp.). BMC Plant Biol 2011, 11:56.

38. Guimarães PM, Garsmeur O, Proite K, Leal-Bertioli SCM, Seijo G, Chaine C, Bertioli DJ, D'Hont A: BAC libraries construction from the ancestral diploid genomes of the allotetraploid cultivated peanut. BMC Plant Biol 2008, 8:14

39. Hunter S, Apweiler R, Attwood TK, Bairoch A, Bateman A, Binns D, Bork P, Das U, Daugherty L, Duquenne L, Finn RD, Gough J, Haft D, Hulo N, Kahn D, Kelly E, Laugraud A, Letunic I, Lonsdale D, Lopez R, Madera M, Maslen J, McAnulla C, McDowall J, Mistry J, Mitchell A, Mulder N, Natale D, Orengo C, Quinn AF, Delengut JD, Sigrist CJA, Thimma M, Thomas PD, Valentin $F$, Wilson $D, W u C H$, Yeats $C$ : InterPro: the integrative protein signature database. Nucl Acids Res 2009, 37(Suppl 1):D211-D215.

40. Guo BZ, Chen XP, Hong YB, Liang XQ, Dang P, Brenneman T, Holbrook C, Culbreath A: Analysis of gene expression profiles in leaf tissues of cultivated peanuts and development of EST-SSR markers and gene discovery. Intl J Plant Genomics 2009, doi:10.1155/2009/715605.

41. Temnykh S, DeClerck G, Lukashova A, Lipovich L, Cartinhour S, McCouch S: Computational and experimental analysis of microsatellites in rice (Oryza sativa L.): frequency, length variation, transposon association, and genetic marker potential. Genome Res 2001, 11:1441-1452.

42. Shoemaker RC, Grant D, Olson T, Warren WC, Wing R, et al: Microsatellite discovery from $B A C$ end sequences and genetic mapping to anchor the soybean physical and genetic maps. Genome 2008, 51:294-302.

43. Ohyama A, Asamizu E, Negoro S, Miyatake K, Yamaguchi H, Tabata S, Fukuoka H: Characterization of tomato SSR markers developed using BAC-end and CDNA sequences from genome databases. Mol Breeding 2009, 23:685-691.

44. McNeil MD, Kota R, Paux E, Dunn D, McLean R, Feuillet C, Li D, Kong X, Lagudah E, Zhang JC, Jia JZ, Spielmeyer W, Bellgard M, Appels R: BACderived markers for assaying the stem rust resistance gene, $S r 2$, in wheat breeding programs. Mol Breeding 2008, 22:15-24.

45. David P, Sevignac M, Thareau V, Catillon Y, Kami J, Gepts P, Langin T, Geffroy $V: B A C$ end sequences corresponding to the B4 resistance gene 
cluster in common bean: a resource for markers and synteny analyses. Mol Genet Genomics 2008, 280:521-533.

46. Burstin J, Deniot G, Potier J, Weinachter C, Aubert G, Baranger A: Microsatellite polymorphism in Pisum sativum. Plant Breeding 2001, 120:311-317.

47. Hong CP, Piao ZY, Kang TW, Batley J, Yang TJ, Hur YK, Bhak J, Park BS, Edwards D, Lim YP: Genomic distribution of simple sequence repeats in Brassica rapa. Mol Cells 2007, 23(3):349-356.

48. Halward TM, Stalker HT, Kochert G: Development of an RFLP linkage map in diploid peanut species. Theor Appl Genet 1993, 87:379-384.

49. Burow MD, Simpson CE, Starr JL, Paterson AH: Transmission genetics of chromatin from a synthetic amphidiploid to cultivated peanut (Arachis hypogaea $\mathrm{L}$.) broadening the gene pool of a monophyletic polyploidy species. Genetics 2001, 159:823-837.

50. Hong YB, Chen XP, Liang XQ, Liu HY, Zhou GY, Li SX, Wen SJ, Holbrook CC, Guo BZ: A SSR-based composite genetic linkage map for the cultivated peanut (Arachis hypogaea L.) genome. BMC Plant Biol 2010, 10:17.

51. Strachan T, Read AP: Human Molecular Genetics II. 2 edition. Oxford: BIOS Scientific Publishers Ltd; 1999.

52. Luo MC, Thomas C, You FM, Hsiao J, Ouyang S, Buell CR, Malandro M, McGuire $P E$, Anderson $O D$, Dvorak J: High-throughput fingerprinting of bacterial artificial chromosomes using the SNaPshot labeling kit and sizing of restriction fragments by capillary electrophoresis. Genomics 2003, 82:378-389.

53. Varshney RK, Thiel T, Stein N, Langridge P, Graner A: In silico analysis on frequency and distribution of microsatellites in ESTs of some cereal species. Cell Mol Biol Lett 2002, 7:537-546.

54. Thiel T, Michalek W, Varshney RK, Graner A: Exploiting EST databases for the development and characterization of gene derived SSR-markers in barley (Hordeum vulgare L.). Theor Appl Genet 2003, 106:411-422.

55. Rozen S, Skaletsky HJ: Primer3 on the WWW for general users and for biologist progrmmers. In Bioinformatics Methods And Protocols: Methods in Molecular Biology. Edited by: Krawetz S, Misener S. Totowa: Humana Press; 2000:365-386.

56. Botstein D, White RL, Skolnick M, Davis RW: Construction of a genetic linkage map in man using restriction fragment length polymorphisms. Am J Hum Genet 1980, 32:314-331.

57. Holbrook CC, Culbreath AK: Registration of 'Tifrunner' peanut. J Plant Reg 2007, 1:124

58. Liang X, Holbrook CC, Lynch RE, Guo BZ: Beta-1,3-glucanase activity in peanut seed (Arachis hypogaea) is induced by inoculation with Aspergillus flavus and copurifies with a conglutin-like protein. Phytopathology 2005, 95:506-511.

59. Murray MG, Thompson WF: Rapid isolation of high molecular weight plant DNA. Nucleic Acids Res 1980, 8:4321-4325.

60. Hu Jinguo, Vick BA: Target region amplification polymorphism: A novel marker technique for plant genotyping. Plant Mol Biol Reporter 2003, 21:289-294.

61. Li G, Quiros CF: Sequence-related amplified polymorphism (SRAP), a new marker system based on a simple PCR reaction: Its application to mapping and gene tagging in Brassica. Theor Appl Genet 2001, 103:455-461.

62. Kosambi DD: The estimation of map distances from recombination values. Ann Eugen 1944, 12:172-175.

doi:10.1186/1471-2229-12-10

Cite this article as: Wang et al: Development and characterization of BAC-end sequence derived SSRs, and their incorporation into a new higher density genetic map for cultivated peanut (Arachis hypogaea L.). BMC Plant Biology 2012 12:10.

\section{Submit your next manuscript to BioMed Central and take full advantage of:}

- Convenient online submission

- Thorough peer review

- No space constraints or color figure charges

- Immediate publication on acceptance

- Inclusion in PubMed, CAS, Scopus and Google Scholar

- Research which is freely available for redistribution

Submit your manuscript at www.biomedcentral.com/submit
Ciomed Central 